\title{
Thermodynamic Framework for Cryogenic Carbon Capture
}

\author{
Laura A. Pellegrini, ${ }^{\mathrm{a}^{*}}$ Giorgia De Guido, ${ }^{\mathrm{a}}$ Stefania Ingrosso ${ }^{\mathrm{b}}$ \\ ${ }^{a}$ Dipartimento di Chimica, Materiali e Ingegneria Chimica “G. Natta”, Politecnico di \\ Milano, Piazza Leonardo da Vinci 32, I-20133 Milan, Italy \\ bSAIPEM S.p.A., via Martiri di Cefalonia 67, I-20097 San Donato Milanese (MI), Italy \\ laura.pellegrini@polimi.it
}

\begin{abstract}
Carbon dioxide capture and storage (CCS) is an important option for climate change mitigation and it has been extensively analysed in recent years to face the climate challenge.

A portion of the emitted $\mathrm{CO}_{2}$ comes from fossil fuel power plants. Several post-combustion technologies are available for separating $\mathrm{CO}_{2}$ from the flue gases produced by the combustion of fossil fuels. In recent years, low-temperature/cryogenic technologies (e.g., $\mathrm{CO}_{2}$ capture by anti-sublimation) have been investigated for this purpose, which rely on the fact that $\mathrm{CO}_{2}$ can be separated out of flue gas by freezing it out. As a consequence, when dealing with the design of this type of processes, it is of paramount importance to be able to satisfactorily predict the thermodynamic phase behaviour of the system of interest, which involves equilibrium conditions also in the presence of solid $\mathrm{CO}_{2}$.

The classical approach for phase equilibria calculations involving a solid phase is based on the equality of components' fugacities in the different phases and on the use of an expression for the fugacity of the freezing component in the solid phase that can be derived by relating it to its fugacity in the vapor phase following a proper thermodynamic cycle. This work compares the predictions for solid-vapor equilibria (SVE) conditions of a flue gas mixture that are obtained using such a classical approach with those obtained using the RGibbs calculation block available in Aspen Plus ${ }^{\circledR}$ process simulator. The latter one enables SVE calculations by minimizing the Gibbs energy. The obtained results are useful for determining suitable operating conditions for the separation process, depending on the desired level of $\mathrm{CO}_{2}$ recovery to be achieved.
\end{abstract}

Keywords: $\mathrm{CO}_{2}$, carbon capture, solid-vapor equilibria, cryogenic gas separation, flue gas

\section{Introduction}

Climate change represents a serious challenge the world has to face today. At the $21^{\text {st }}$ Conference held in Paris in 2015, Parties in the United Nations Framework Convention on Climate Change reached an agreement to combat this issue and to accelerate and intensify the actions and investments needed for a sustainable low carbon future. In this context, CCS techniques have been extensively studied in recent years as a mitigation option for reducing anthropogenic $\mathrm{CO}_{2}$ emissions into the atmosphere.

Different technologies are currently available for $\mathrm{CO}_{2}$ removal from flue gases, including chemical (De Guido et al., 2018) and physical absorption, adsorption (Gutierrez-Ortega et al., 2017), permeation through membranes (Leimbrink et al., 2015) 
and low-temperature or commonly referred to as "cryogenic" separation. Recently, a great attention has been devoted to cryogenic separation methods for application not only to natural gas purification (De Guido et al., 2015) and biogas upgrading (Pellegrini et al., 2017), but also to nitrogen rejection (De Guido et al., 2019) and $\mathrm{CO}_{2}$ capture from flue gas. When this last application is considered, the separation process aims at reducing the flue gas temperature from ambient to a low temperature range at which $\mathrm{CO}_{2}$ freezes out and can be removed from the main gas stream in a solid phase. The advantages of this technology can be summarized as follows: liquid $\mathrm{CO}_{2}$ is directly produced, thus making it relatively easy to be stored or to be used for Enhanced Oil Recovery; the use of solvents is avoided (Sipöcz et al., 2013). Certainly, a major disadvantage consists in the large amount of energy required for refrigeration. However, literature works have proved that the use of low-temperature technologies for natural gas purification becomes less energy demanding at $\mathrm{CO}_{2}$ concentrations higher than 8-9 mol\% (Langè et al., 2015).

Clodic et al. (Clodic et al., 2005) proposed a cryogenic technology for $\mathrm{CO}_{2}$ separation from the flue gases for a conventional pulverized coal-fired power boiler, which is based on $\mathrm{CO}_{2}$ frosting (anti-sublimation) and defrosting at atmospheric pressure in a low-temperature evaporator. Baxter et al. (Baxter et al., 2009) proposed the CCC $^{\mathrm{TM}}$ (Cryogenic $\mathrm{CO}_{2}$ Capture ${ }^{\mathrm{TM}}$ ) technology, which uses a phase change to separate $\mathrm{CO}_{2}$ from exhaust or process gases, i.e. by forming solid $\mathrm{CO}_{2}$ (desublimation). Tuinier et al. (Tuinier et al., 2010) developed a novel post-combustion $\mathrm{CO}_{2}$ capture process concept, based on cryogenic $\mathrm{CO}_{2}$ freeze-out in dynamically operated packed beds. Song et al. (Song et al., 2012) developed a novel cryogenic $\mathrm{CO}_{2}$ capture system based on the use of Stirling coolers, which is able to condense and separate $\mathrm{CO}_{2}$ from flue gas according to differences in condensation and desublimation.

The increased interest in this type of process requires a proper tool to be available for the correct prediction of phase equilibria also involving the solid phase. In this work, a method based on a classical approach is presented and results are compared with those found in the literature and the ones that can be obtained using a tool available in a commercial process simulator. These results are exploited to establish the suitable operating conditions for $\mathrm{CO}_{2}$ separation from flue gas by a cryogenic separation method.

\section{Methods}

\subsection{Proposed thermodynamic approach for SVE calculations}

In this work, a classical approach has been used (it will be referred to as "proposed approach” in the following) to solve a two-phase solid-vapor equilibrium (SVE) problem for a flue gas mixture having the composition reported in Table 1.

Table 1. Composition (molar fractions) of the flue gas mixture.

\begin{tabular}{ll}
\hline Component & $\mathbf{m o l} \%$ \\
\hline $\mathrm{CO}_{2}$ & 14.0 \\
$\mathrm{~N}_{2}$ & 83.0 \\
$\mathrm{O}_{2}$ & 3.0 \\
\hline
\end{tabular}

Since the number and type of phases present at equilibrium are not known a-priori, the choice of studying SVE conditions for the system of interest has to be considered as an assumption based on the type of components the system consists of.

The SVE problem has been solved assigning the pressure and recovery of $\mathrm{CO}_{2}$ with the aim of plotting the equilibrium temperature curve as a function of pressure for each 
recovery level. In particular, three values have been chosen for that (i.e., $90 \%$, $95 \%$ and $99 \%$ ) for comparison of the results obtained in this work with those presented in the literature (Baxter et al., 2009). The recovery of $\mathrm{CO}_{2}$ in the solid phase (REC) is calculated according to Eq. (1):

$R E C=\frac{S \cdot x_{\mathrm{CO}_{2}}^{S}}{F \cdot z_{\mathrm{CO}_{2}}}=\frac{S}{F \cdot z_{\mathrm{CO}_{2}}}$

In Eq. (1), $x_{\mathrm{CO}_{2}}^{\mathrm{S}}$, which denotes the molar fraction of $\mathrm{CO}_{2}$ in the solid phase, has been set equal to one since the solid phase is assumed to consist of pure $\mathrm{CO}_{2}$. Moreover, in Eq. (1) $F$ and $S$ denote the molar flow rates, respectively, of the feed stream and of the solid phase, and $\mathrm{z}_{\mathrm{CO}_{2}}$ refers to the molar fraction of $\mathrm{CO}_{2}$ in the feed stream (i.e., 0.14). By combining Eq. (1) with the material balances on the species involved in the investigated system, it is possible to get the composition of the vapor phase at equilibrium for each case study (i.e., each pair of pressure and $\mathrm{CO}_{2}$ recovery). The SVE calculation is based on the equality of fugacity of each $i$-th component in the two considered phases (i.e., solid and vapor), and Eq. (2) holds:

$$
\hat{f}_{i}^{S}\left(T, P, \underline{x}^{S}\right)=\hat{f}_{i}^{V}\left(T, P, \underline{x}^{V}\right)
$$

Since $\mathrm{CO}_{2}$ is the only species to be present in both phases at equilibrium, Eq. (2) can be rewritten, according to the classical method, as Eq. (3), where $\phi_{\mathrm{CO}_{2}}^{V}$ is the fugacity coefficient of pure $\mathrm{CO}_{2}$ in the vapor phase evaluated at the sublimation pressure, $P_{\mathrm{CO}_{2}}^{\text {subl }}$, and equilibrium temperature, $T$, and $\hat{\phi}_{\mathrm{CO}_{2}}^{V}$ is the fugacity coefficient of $\mathrm{CO}_{2}$ in the vapor mixture evaluated at the equilibrium temperature, at the given pressure, $P$, of the system and composition.

$\phi_{\mathrm{CO}_{2}}^{V}\left(T, P_{\mathrm{CO}_{2}}^{\text {subl }}(T)\right) \cdot P_{\mathrm{CO}_{2}}^{\text {subl }}(T) \cdot \exp \left(\frac{v_{\mathrm{CO}_{2}}^{S} \cdot\left(P-P_{\mathrm{CO}_{2}}^{\text {subl }}(T)\right)}{R T}\right)=P \cdot x_{\mathrm{CO}_{2}}^{V} \cdot \hat{\phi}_{\mathrm{CO}_{2}}^{V}\left(T, P, \underline{x}^{V}\right)$

The two fugacity coefficients in Eq. (3) have been calculated using the Peng-Robinson Equation of State (Peng and Robinson, 1976). As for the binary interaction parameters, the values have been taken from the Aspen Hysys ${ }^{\circledR}$ V9.0 database (AspenTech, 2016a). Therefore, Eq. (3) can be solved in the unknown temperature, at given pressure and $\mathrm{CO}_{2}$ recovery. The solid molar volume, $v_{\mathrm{CO}_{2}}^{S}$, in the Poynting correction term has been assumed to be constant and equal to $0.0282 \mathrm{~m}^{3} / \mathrm{kmol}$. As for the sublimation pressure, $P_{\mathrm{CO}_{2}}^{\text {subl }}$, it has been computed using the expression proposed by Jensen et al. (Jensen et al., 2015) and reported in Eq. (4), where $P_{\mathrm{CO}_{2}}^{\text {subl }}$ is in $\mathrm{Pa}$ and $T$ in $\mathrm{K}$.

$$
P_{\mathrm{CO}_{2}}^{\text {subl }}(T)=\exp \left(57.52-\frac{3992.84}{T}-4.9003 \cdot \ln (T)+2.415 \cdot 10^{-15} T^{6}+\frac{8125.6}{T^{2}}\right)
$$

\subsection{Thermodynamic approach available in the process simulator}

The RGibbs reactor is the only calculation block available in Aspen Plus ${ }^{\circledR}$ V9.0 (AspenTech, 2016b) that is able to solve a system involving phase equilibria also in the presence of a solid phase (Schach et al., 2011). It uses Gibbs energy minimization 
techniques, instead of methods based on the equality of fugacities of each component in each phase. The system is considered at equilibrium when the distribution of the components corresponds to the minimum of the Gibbs energy (subject to atom balance constraints). According to the literature from Aspen Technology, this method can be used for any number of phases and components and always yields stable solutions.

\section{Results and discussion}

Before solving the SVE problem investigated in this work with the proposed approach, the reliability of Eq. (4) in predicting the $\mathrm{CO}_{2}$ sublimation pressure has been checked. Results are shown in the parity plot in Fig. 1. They suggest a good agreement between calculated and experimental values (Fernández-Fassnacht and Del Río, 1984; Levenson, 1974), with an average absolute deviation of $23.6 \%$.

Fig. 2 illustrates the results obtained using the proposed approach (dashed line), which are compared with those obtained using the RGibbs tool available in Aspen Plus ${ }^{\circledR}$ V9.0 (dotted lines) and with those available in the literature (Baxter et al., 2009) (solid line). In Fig. 2, the symbols refer to the points of the curves where each approach registers a maximum. The proposed approach is about 2 degrees more conservative in correspondence of the value of pressure where the maximum is found in the literature and is in good agreement with the results obtained using the RGibbs tool.

As a general result, it is possible to state that, for achieving a higher recovery at a given pressure, it is necessary to operate the process at a lower temperature. Moreover, the maximum trend the curves in Fig. 2 exhibit suggests that, if a certain $\mathrm{CO}_{2}$ recovery is desired, the process can be operated at a higher temperature at increasing pressure and viceversa for pressures up to the labelled maximum point. Beyond the labelled points in Fig. 2, higher pressures and lower temperatures are required to achieve the same $\mathrm{CO}_{2}$ recovery in the solid phase, both of which would make the $\mathrm{CO}_{2}$ separation process more energy-intensive. Therefore, for each curve in Fig. 2, the portion up to the labelled point is the one corresponding to the operating conditions of interest for the process, which aims at separating $\mathrm{CO}_{2}$ from a flue gas mixture by desublimation.

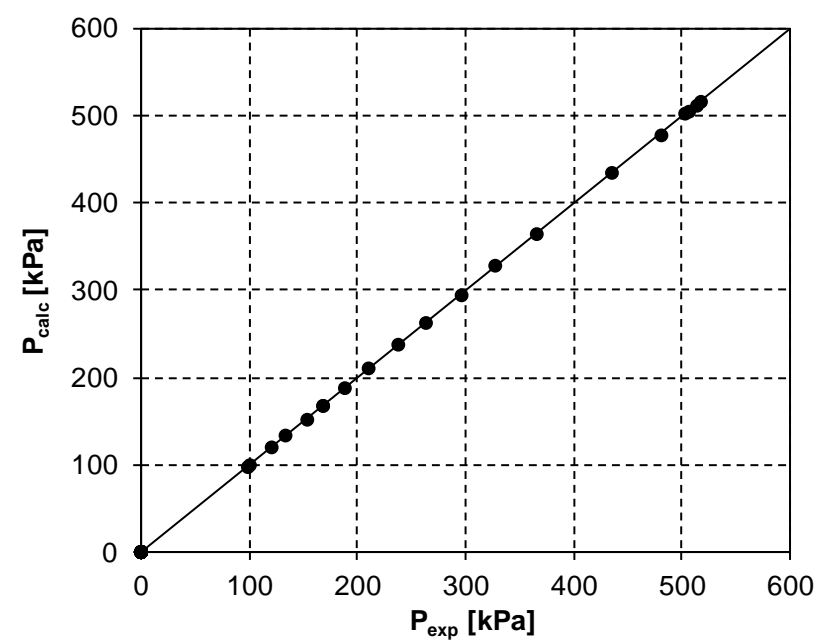

Figure 1. Parity plot for $\mathrm{CO}_{2}$ sublimation pressure. Experimental data have been taken from the literature (Fernández-Fassnacht and Del Río, 1984; Levenson, 1974) and cover the temperature range 69.7-216.6 K; calculated values have been obtained using Eq. (4). 


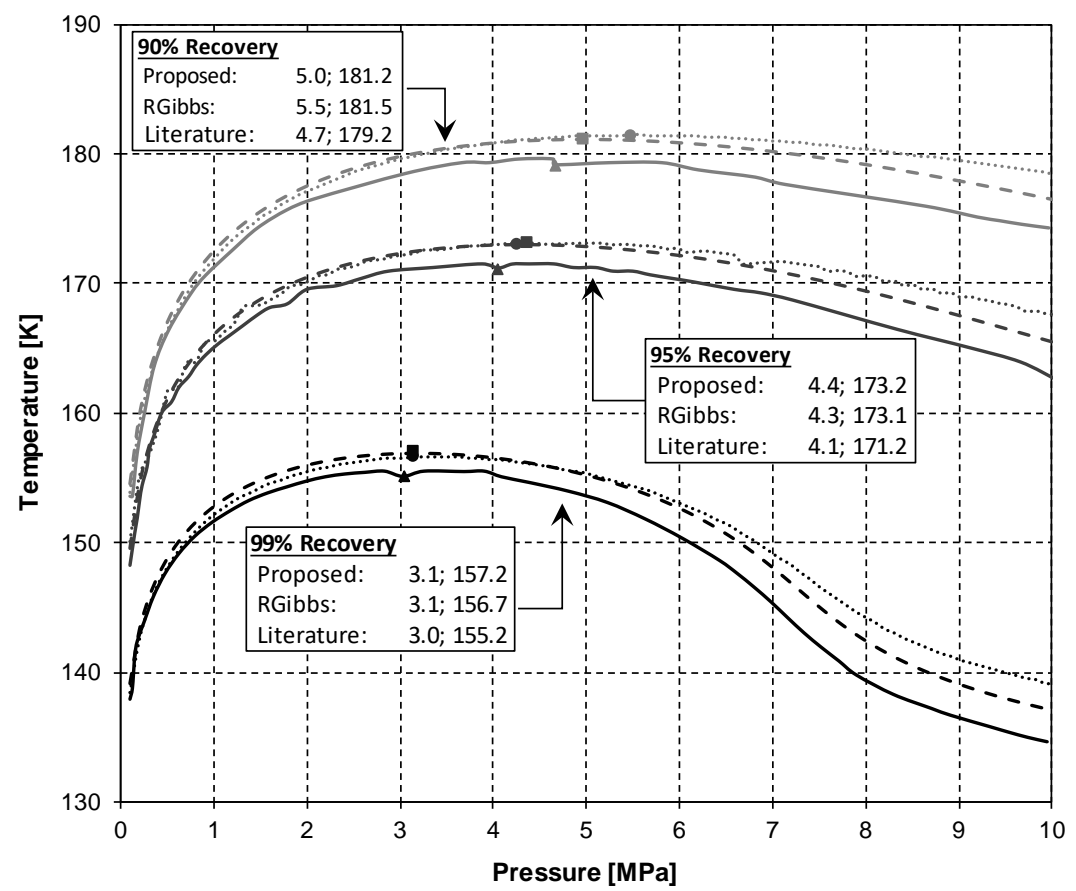

Figure 2. SVE temperatures as a function of pressure at assigned recovery of $\mathrm{CO}_{2}$ in the solid phase. Comparison between the results obtained using: the proposed approach (dashed line), the RGibbs tool of Aspen Plus ${ }^{\circledR}$ V9.0 (AspenTech, 2016b) (dotted line), and the ones presented in the literature (Baxter et al., 2009) (solid line). The different colors refer to different $\mathrm{CO}_{2}$ recovery values: 90 \% (light grey); $95 \%$ (grey); 99 \% (black). For each curve, the symbols (square: proposed approach; circle: RGibbs; triangle: literature) refer to the values in the text box that correspond to the pressure at which each approach registers the maximum temperature.

\section{Conclusions}

Low-temperature or cryogenic technologies for $\mathrm{CO}_{2}$ capture from flue gases have received great attention in the last years to cope with the disadvantages of conventionally adopted technologies mainly based on absorption. Since these novel separation methods are operated at conditions where $\mathrm{CO}_{2}$ freezes out, it is important to have a tool capable of satisfactorily predicting phase equilibria in the presence of a solid phase, which is not always taken into account in phase equilibria calculations. This is important for a correct process design.

In this work, a calculation method is proposed for this purpose and the obtained results are compared with those of a calculation block available in a commercial process simulator, based on a different approach. The good agreement suggests that the proposed method can be used to design the $\mathrm{CO}_{2}$ separation process.

In particular, for achieving $99 \%$ recovery of $\mathrm{CO}_{2}$ in the solid phase, temperatures of about $140 \mathrm{~K}$ have to be reached at atmospheric pressure or higher temperatures (up to about $155 \mathrm{~K}$ ) at increasing pressures up to about $3 \mathrm{MPa}$. Above this pressure value, due to the maximum trend exhibited by the temperature-pressure curve at fixed $\mathrm{CO}_{2}$ recovery, the process should be operated at lower temperatures, which is disadvantageous since this makes it more energy-intensive. 
For an improved analysis, an advanced phase equilibria calculation method has been developed in the framework of a joint project between the GASP group of Politecnico di Milano and Saipem S.p.A. and implemented in the "SLVEcalc" tool. The advanced model takes into account the phase stability analysis (Gupta, 1990) for the identification of the type of phases present at equilibrium and will be the subject of a future work.

\section{References}

AspenTech, 2016a. Aspen Hysys ${ }^{\circledR}$. AspenTech, Burlington (MA), United States. AspenTech, 2016b. Aspen Plus ${ }^{\circledR}$. AspenTech, Burlington (MA), United States.

L. Baxter, A. Baxter, S. Burt, 2009. Cryogenic $\mathrm{CO}_{2}$ capture as a cost-effective $\mathrm{CO}_{2}$ capture process, International Pittsburgh Coal Conference, Pittsburgh, USA.

D. Clodic, R. El Hitti, M. Younes, A. Bill, F. Casier, 2005. $\mathrm{CO}_{2}$ capture by anti-sublimation

Thermo-economic process evaluation, $4^{\text {th }}$ Annual Conference on Carbon Capture and

Sequestration. National Energy Technology Laboratory Alexandria (VA) USA, pp. 2-5.

G. De Guido, M. Compagnoni, L.A. Pellegrini, I. Rossetti, 2018. Mature versus emerging technologies for $\mathrm{CO}_{2}$ capture in power plants: Key open issues in post-combustion amine scrubbing and in chemical looping combustion. Frontiers of Chemical Science and Engineering $12,315-325$.

G. De Guido, S. Langè, L.A. Pellegrini, 2015. Refrigeration cycles in low-temperature distillation processes for the purification of natural gas. Journal of Natural Gas Science and Engineering 27, 887-900.

G. De Guido, F. Messinetti, E. Spatolisano, 2019. Cryogenic nitrogen rejection schemes: analysis of their tolerance to $\mathrm{CO}_{2}$. Industrial \& Engineering Chemistry Research 58, 17475-17488.

E. Fernández-Fassnacht, F. Del Río, 1984. The vapour pressure of $\mathrm{CO}_{2}$ from 194 to $243 \mathrm{~K}$. The Journal of Chemical Thermodynamics 16, 469-474.

A.K. Gupta, 1990. Steady state simulation of chemical processes. Chemical and Petroleum Engineering, University of Calgary.

A. Gutierrez-Ortega, J. Menacho, R. Gonzalez-Olmos, R. Nomen, J. Sempere, 2017. Numerical simulation of fixed bed for $\mathrm{CO}_{2}$ capture in a fossil fuel emission points by Pressure Swing Adsorption system, Computer Aided Chemical Engineering. Elsevier, pp. 415-420.

M.J. Jensen, C.S. Russell, D. Bergeson, C.D. Hoeger, D.J. Frankman, C.S. Bence, L.L. Baxter, 2015. Prediction and validation of external cooling loop cryogenic carbon capture (CCC-ECL) for full-scale coal-fired power plant retrofit. International Journal of Greenhouse Gas Control 42, 200-212.

S. Langè, L.A. Pellegrini, P. Vergani, M. Lo Savio, 2015. Energy and Economic Analysis of a New Low-Temperature Distillation Process for the Upgrading of High- $\mathrm{CO}_{2}$ Content Natural Gas Streams. Industrial \& Engineering Chemistry Research 54, 9770-9782.

M. Leimbrink, A.-K. Kunze, D. Hellmann, A. Górak, M. Skiborowski, 2015. Conceptual Design of Post-Combustion $\mathrm{CO}_{2}$ Capture Processes-Packed Columns and Membrane Technologies, Computer Aided Chemical Engineering. Elsevier, pp. 1223-1228.

L. Levenson, 1974. Sublimation rates and vapor pressure of $\mathrm{H}_{2} \mathrm{O}, \mathrm{CO}_{2}, \mathrm{~N}_{2} \mathrm{O}$ and Xe. Journal of Chemical \& Engineering Data 19, 107-110.

L.A. Pellegrini, G. De Guido, S. Langé, 2017. Biogas to liquefied biomethane via cryogenic upgrading technologies. Renewable Energy 124, 75-83.

D.-Y. Peng, D.B. Robinson, 1976. A new two-constant equation of state. Industrial \& Engineering Chemistry Fundamentals 15, 59-64.

M.-O. Schach, B. Oyarzún, H. Schramm, R. Schneider, J.-U. Repke, 2011. Feasibility study of $\mathrm{CO}_{2}$ capture by anti-sublimation. Energy Procedia 4, 1403-1410.

N. Sipöcz, A. Hernandez-Nogales, M.A. Gonzalez-Salazar, R. Shisler, V. Lissianski, 2013. Low temperature $\mathrm{CO}_{2}$ capture for near-term applications. Energy Procedia 37, 1228-1238.

C.-F. Song, Y. Kitamura, S.-H. Li, K. Ogasawara, 2012. Design of a cryogenic $\mathrm{CO}_{2}$ capture system based on Stirling coolers. International Journal of Greenhouse Gas Control 7, 107-114. M. Tuinier, M. van Sint Annaland, G.J. Kramer, J. Kuipers, 2010. Cryogenic $\mathrm{CO}_{2}$ capture using dynamically operated packed beds. Chemical Engineering Science 65, 114-119. 